Surgical technique

\title{
Portal Vein Anastomosis with Parachute Method in Hepatectomy and Pancreatectomy
}

Atsushi Nanashima, MD, Takafumi Abo, MD, Masaki Kunizaki, MD, Hiroaki Takeshita, MD, Shigekazu Hidaka, MD, Terumitsu Sawai, MD, Takeshi Nagayasu, MD

Division of Surgical Oncology, Department of Translational Medical Sciences, Nagasaki University Graduate School of Biomedical Sciences, 1-7-1 Sakamoto, Nagasaki 852-8501, Japan

Running title: Parachute anastomosis of portal vein

This study was undertaken without financial support.

Reprint requests to: Atsushi Nanashima

Division of Surgical Oncology, Department of Translational Medical Sciences, Nagasaki University Graduate School of Biomedical Sciences, 1-7-1 Sakamoto, Nagasaki 852-8501, JAPAN

Tel.: +81-95-849-7304 , Fax: +81-95-849-7306

E-mail: a-nanasm@nagasaki-u.ac.jp 


\section{ABSTRACT}

In advanced cancers of hepatobiliary and pancreatic lesions, major vascular resection and reconstruction are necessary to accomplish curative resection. Stenosis of vascular anastomosis is a concern in case of portal or superior mesenteric venous anastomosis with different vascular calibers. We attempted to apply parachute anastomosis in such a situation, which has often been used in the field of cardiovascular surgery. We applied this procedure in 4 cases of two hepatectomies in intrahepatic cholangiocarcinomas and two pancreatectomies in pancreatic carcinomas, in which combined vascular resection was necessary. After anastomosis, the orifice of anastomotic veins was well matched and did not show stenosis or poor blood flow on ultrasonographic examination. Parachute anastomosis in the portal or superior mesenteric vein is a useful procedure to prevent vascular stenosis, particularly in case of anastomosis with different calibers.

KEYWORDS: Vascular resection, Hepatectomy, Pancreatectomy, Anastomosis, Parachute technique

ABBREVIATIONS: Portal vein (PV), Superior mesenteric vein (SMV) 


\section{INTRODUCTION}

In the recent years, combined resection of the portal trunk vein (PV) or superior mesenteric vein (SMV) is often performed in patients with advanced hepatobiliary and pancreatic malignancies $(1,2)$, and the resectability of these malignancies has been improved with the improvement of operative techniques for vascular resection $(3,4)$. In case of longer resection of PV or SMV, the caliber of the venous orifice between anastomosed veins is sometimes different. To match the different calibers while avoiding anastomotic stenosis, oblique cut-end or longitudinal cut at the orifice of the smaller vein has been devised. In the field of cardiovascular surgery, the procedure of parachute anastomosis has often been applied for arterial or venous anastomosis (5, 6). However, to our knowledge, this technique has rarely been applied in the field of abdominal surgery at this stage. We recently attempted this technique for vascular anastomosis for different calibers in PV or SMV, and we had a good outcome in 4 cases. In the present report, we introduce this anastomotic technique in patients who underwent hepatectomy and pancreatectomy. 


\section{METHODOLOGY}

\section{Operative procedures}

In liver resection, hepatic parenchymal transection and transection of hilar bile duct was performed prior to PV anastomosis. We routinely clamped the hepatoduodenal ligament to occlude total inflow to the liver during transection (Pringle’s maneuver) and used the forceps fracture method (7) and an ultrasonic dissector (USU MH-207, Olympus, Tokyo, Japan) for the transection of liver parenchyma. In pancreatectomy, resection of the pancreas was also performed prior to SMV resection. Passive bypass using an Anthron bypass catheter (Toray Medical, Tokyo) between the superior mesenteric vein and umbilical vein was not used during anastomosis in the preset cases (8). For PV or SMV anastomosis, direct end-to-end anastomosis using 5-0 Proline (Ethicon Inc., Cornelia, GA) was used to reconstruct both veins in this series.

Transected veins were clamped and accurately fixed to match the caliber without kinking. Parachute anastomosis was performed as follows: in the first stitch, sutured thread was not tied and very loosely sutured in the posterior wall of veins by the continuous intra-luminal anastomosis (Figure 1a) $(5,6)$. After suturing the posterior wall, each thread was pulled toward the other side along the orifice (Figure 1b) and then anastomosis of the posterior wall was accomplished. Another needle thread was used for suturing the conventional running suture (Figure 1c) and, finally, both threads were loosely tied. 


\section{Case presentation}

We experienced two patients with intrahepatic cholangiocarcinomas involving bifurcation of the portal trunk vein (PV) in the hepatic hilum (Figure 2a). Left hepatectomy combined resection of right PV was chosen in intrahepatic cholangiocarcinomas. In these cases, orifice of the remnant right PV was thought to be smaller than that of the main PV trunk. Anastomosed PV showed no stenosis or kink (Figure 2b).

Two cases with pancreatic carcinomas involved the superior mesenteric vein (SMV), one located in the pancreatic uncinate (Figure 3a) and another located in the pancreatic body (Figure 3b). One case underwent pancreaticoduodenectomy and another underwent distal pancreatectomy with en-block celiac axis resection (DP-CAR) (9). In the latter case, the conventional suturing technique was attempted; however, the anastomotic vein was severely kinked. Then, the anastomosis was again resumed by the parachute anastomosis, which eventually showed good anastomosis with good blood flow (Figure 3c).

After surgery, the blood flow of the vascular anastomosis was checked by Doppler ultrasonography or enhanced computed tomography after operation. There were no vascular complications and no liver dysfunction during the hospital stay and after discharge. 


\section{DISCUSSION}

Aggressive surgical exploration for hepatobiliary malignancy combined with vascular resection has been reported $(1-4,9-11)$ and the techniques and perioperative management have remarkably improved. Our group has actively performed vascular resection for complete tumor resections (R0) during the last decade (12). Regarding hepatic resection, the hepatic vein, vena cava, portal vein and hepatic artery are the target of combined resection (13-15). With respect to PV invasion, intrahepatic cholangiocarcinoma or hilar bile duct carcinoma frequently involve the neighboring vessels $(16,17)$. Usually, the techniques of portal resection and anastomosis are not particularly difficult in comparison with other major vessels. End-to-end anastomosis between portal veins is also technically possible. However, in some cases, smaller portal veins must be anastomosed to the main portal trunk or SMV in case wide resection of the vein is necessary. When the caliber of veins is different, techniques to match the orifice are necessary to avoid vascular stenosis or kink. As the present report showed, parachute anastomosis is feasible for such a PV or SMV anastomosis. This technique is basically applied for arterial anastomosis in cardiovascular surgery $(5,6)$ and this procedure is mainly applied for end-to-side anastomosis, in which it would be difficult to have an adequate orifice. Therefore, the parachute technique is used to create an adequate orifice in such cases. In hepato-biliary-pancreas surgery, side-to-end anastomosis is not applied; however, the parachute technique is useful in cases of difficult end-to-end anastomosis. This technique is not difficult in comparison with other devised techniques. Usually, we 
performed two-stay suture for intra-laminar and running vascular anastomosis. By using this technique, it is likely to create a narrow anastomosis in some cases because modification of suture during anastomosis is difficult by fixation of two points. In case of parachute anastomosis without stay suture, modification during suture is possible. In case of DP-CAR, PV and SMV were fixed with the pancreatic head and, therefore, direct end-to-end anastomosis might be difficult. Indeed, in the present case of DP-CAR, the first anastomosis by conventional suturing resulted in severe stenosis with vulvulus. The second anastomosis by parachute technique solved this problem. In the present series, no problems of parachute anastomosis were observed, and postoperative blood flow was adequate. This suturing technique is applied for pancreatic duct or bile duct anastomosis and leakage of pancreatic or bile juice tended to be improved $(18,19)$. In thoracic surgery, this technique is applied for bronchial anastomosis at our institute (data not published). Therefore, the parachute anastomosis technique can be applied in various duct anastomoses in general surgery.

In conclusion, we applied the parachute procedure for end-to-end vascular anastomosis of PV or SMV in hepato-biliary and pancreas resections. When the smaller vein must be anastomosed with the major trunk, parachute anastomosis is useful to prevent stenosis or kink. Adequate anastomosis adjusted vascular caliber and good blood flow could be obtained after surgery in the present 4 cases. Future study and appropriate analysis regarding this surgical technique in a large number of patients is necessary to evaluate feasibility. 


\section{Figure legend}

Figure 1. Technique of parachute anastomosis. (a) Needle and thread were loosely sutured in the posterior wall of veins. (b) After suturing the posterior wall, each thread was pulled toward the other side along the orifice. (c) Anterior wall was sutured along the conventional running suture.

Figure 2. (a) Case of intrahepatic cholangiocarcinomas involving portal vein in the hepatic hilum. (b) Anastomosed PV showed no stenosis or kink.

Figure 3. (a) pancreatic carcinomas located in the pancreatic uncinate involving superior mesenteric vein. (b) pancreatic carcinoma located in the pancreatic body involving the superior mesenteric vein. (c) Anastomosis by parachute anastomosis showed good anastomosis with good blood flow. 


\section{REFERENCES}

1. Nimura Y: Extended surgery in bilio-pancreatic cancer: the Japanese experience. Semin Oncol 2002;29:17-22

2. Lang H, Sotiropoulos GC, Fruhauf NR, Domland M, Paul A, Kind EM, Malago M, Broelsch CE: Extended hepatectomy for intrahepatic cholangiocellular carcinoma (ICC): when is it worthwhile? Single center experience with 27 resections in 50 patients over a 5-year period. Ann Surg 2005;22:134-143

3. Li B, Chen FZ, Ge XH, Cai MZ, Jiang JS, Li JP, Lu SH: Pancreatoduodenectomy with vascular reconstruction in treating carcinoma of the pancreatic head. Hepatobiliary Pancreat Dis Int. 2004;3:612-615.

4. Miyazaki M, Ito H, Kimura F, Shimizu H, Togawa A, Ohtsuka M, Yoshidome H, Kato A, Yoshitomi H, Sawada S, Ambiru S: Hepatic vein reconstruction using autologous vein graft for resection of advanced hepatobiliary malignancy. Hepatogastroenterology. 2004;51:1581-1585.

5. Isomura T, Hisatomi K, Hirano A, Nishimi M, Satoh T, Kumate M, Ohishi K: Improvement of postoperative graft patency rate for coronary revascularization. Minerva Cardioangiol. 1995;43:475-479.

6. Falk V, Gummert JF, Walther T, Hayase M, Berry GJ, Mohr FW: Quality of computer enhanced totally endoscopic coronary bypass graft anastomosis--comparison to conventional technique._Eur J Cardiothorac Surg. 1999;15:260-264.

7. Takayama T, Makuuchi M, Kubota K, Harihara Y, Hui AM, Sano K, Ijichi M, Hasegawa K: Randomized comparison of ultrasonic vs clamp transection of the liver. Arch Surg 2001;136:922-928

8. Kusano T, Tamai O, Miyazato H, Isa T, Muto Y, Furukawa M: Extracorporeal bypass using a centrifugal pump during resection of malignant liver tumors. Hepatogastroenterology 1999;46:2483-2489

9. Hirano S, Kondo S, Hara T, Ambo Y, Tanaka E, Shichinohe T, Suzuki O, Hazama K: Distal pancreatectomy with en bloc celiac axis resection for locally advanced pancreatic body cancer: long-term results. Ann Surg.;246:46-51. 
10. Miyazaki M, Ito H, Nakagawa K, Ambiru S, Shimizu H, Ohtuka M, Shimizu Y, Nakajima N, Kimura F: Vascular reconstruction using left renal vein graft in advanced hepatobiliary malignancy. Hepatogastroenterology. 1997;44:1619-1623.

11. Yamamoto Y, Sugihara T, Sasaki S, Furukawa H, Furukawa H, Okushiba S, Nohira K: Microsurgical reconstruction of the hepatic and superior mesenteric arteries using a back wall technique. J Reconstr Microsurg. 1999;15:321-325.

12. Nanashima A, Yamaguchi H, Sumida Y, Abo T, Tobinaga S, Tanaka K, Takeshita H, Hidaka S, Sawai T, Yasutake T, Nagayasu T: Hepatectomy and pancreatectomy with combined vascular resection in patients with hepato-biliary and pancreas diseases at a single cancer institute.Hepatogastroenterology. 2008;55:873-878.

13. Hemming AW, Reed AI, Langham MR Jr, Fujita S, Howard RJ: Combined resection of the liver and inferior vena cava for hepatic malignancy. Ann Surg. 2004;239:712-719.

14. Shimada H, Endo I, Sugita M, Masunari H, Fujii Y, Tanaka K, Misuta K, Sekido H, Togo S: Hepatic resection combined with portal vein or hepatic artery reconstruction for advanced carcinoma of the hilar bile duct and gallbladder. World $\mathrm{J}$ Surg. 2003;27:1137-1142.

\section{Aoki T, Sugawara Y, Imamura H, Seyama Y, Minagawa M, Hasegawa K,}

Kokudo N, Makuuchi M: Hepatic resection with reconstruction of the inferior vena cava or hepatic venous confluence for metastatic liver tumor from colorectal cancer. $\mathrm{J}$ Am Coll Surg. 2004;198:366-372.

16. Miyazaki M, Ito H, Nakagawa K, Ambiru S, Shimizu H, Ohtuka M, Shimizu Y, Nakajima N, Kimura F: Vascular reconstruction using left renal vein graft in advanced hepatobiliary malignancy. Hepatogastroenterology. 1997;44:1619-1623.

17. Tashiro S, Uchino R, Hiraoka T, Tsuji T, Kawamoto S, Saitoh N, Yamasaki K, Miyauchi Y: Surgical indication and significance of portal vein resection in biliary and pancreatic cancer. Surgery. 1991;109:481-487

18. Okamoto K, Koyama I, Toshimitsu Y, Aikawa M, Okada K, Ueno Y, Miyazawa M: Duct-to-mucosa pancreatojejunostomy for small main pancreatic duct by the parachute technique after pancreatoduodenectomy. Hepatogastroenterology. 2011;58:1025-1028. 
Nanashima et al., Page 11 of 11

19. Yoshimi F, Ikeda M, Oka D, Asato Y: Reconstruction of small bile ducts using a parachute technique. Hepatogastroenterology. 2002;49:1213-1215. 


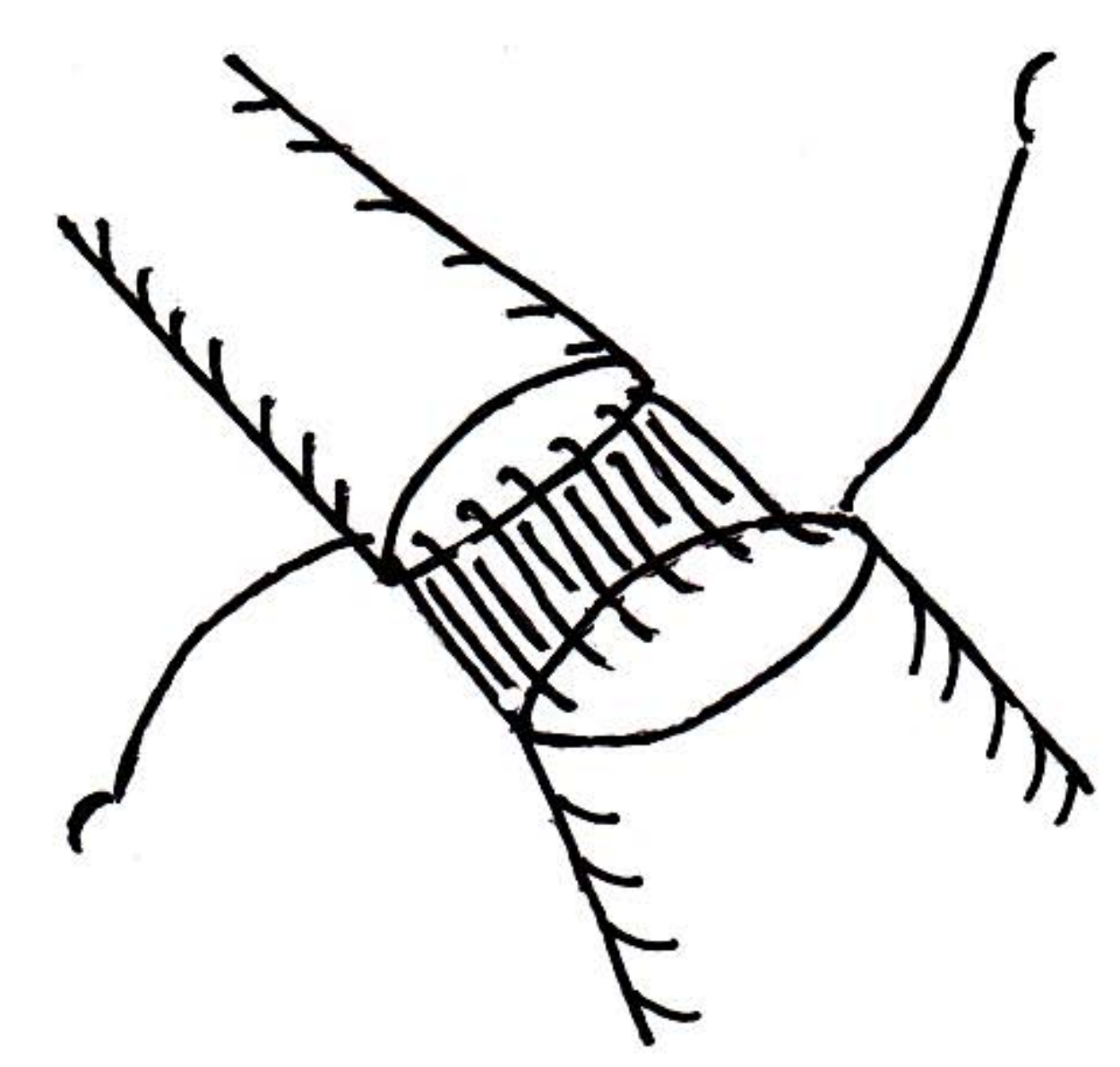


Fig1b

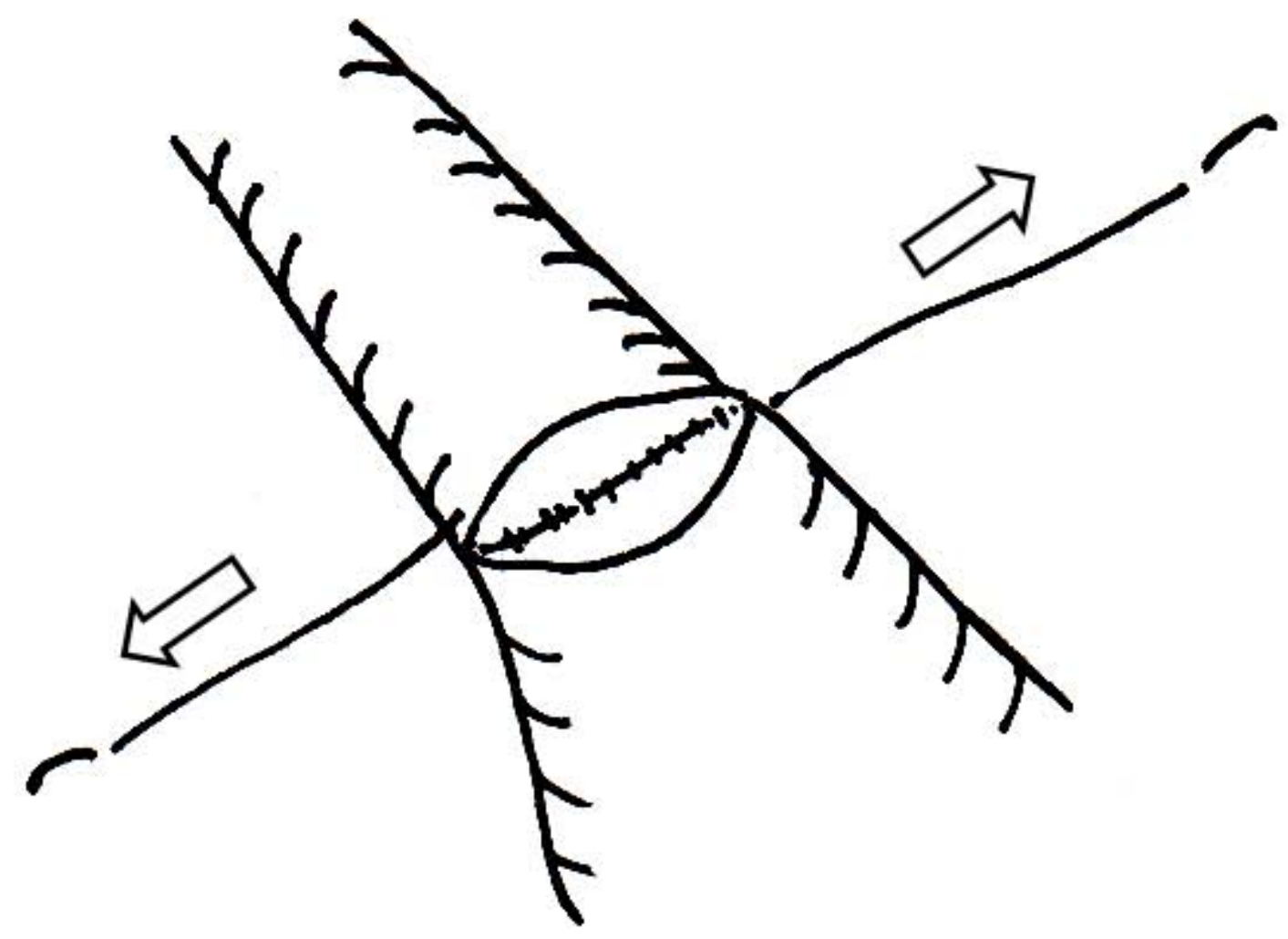


Fig1c

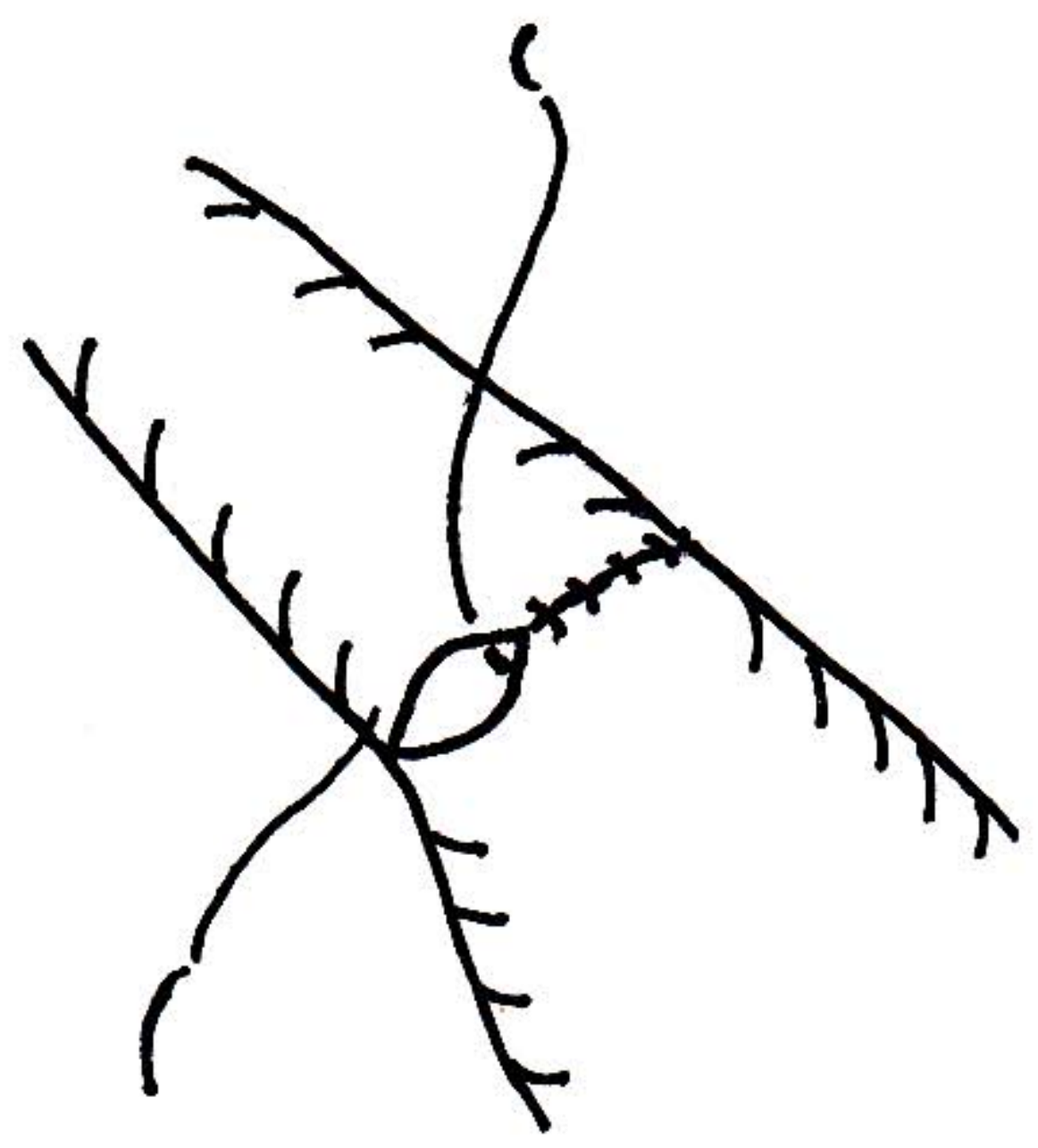


Fig2a

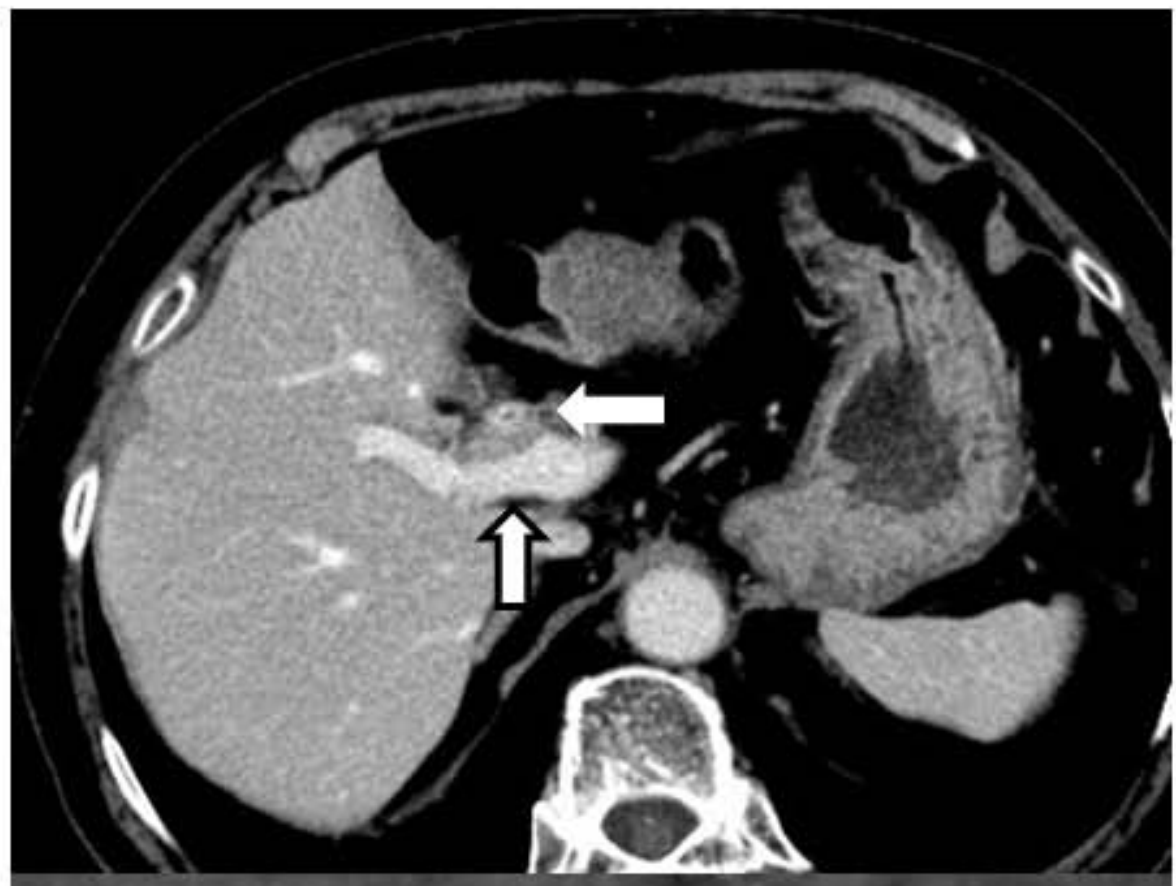

13

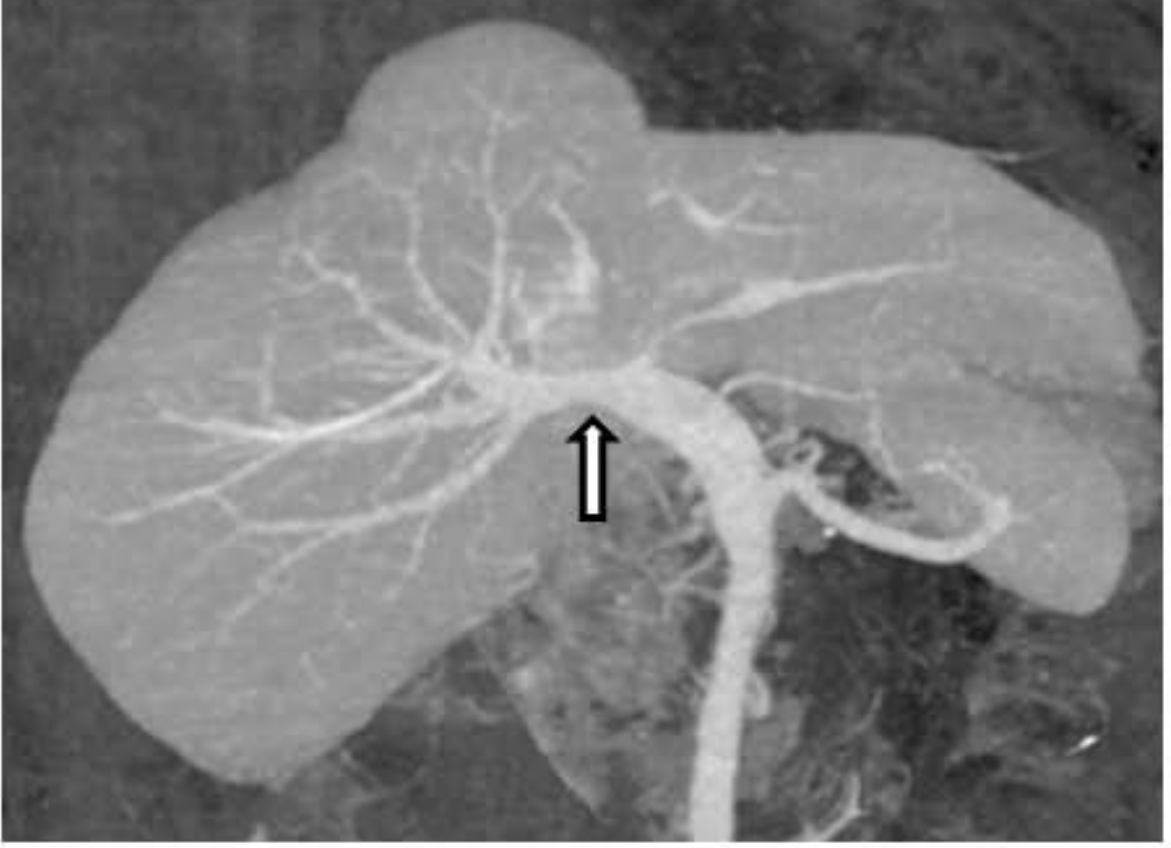


Fig2b

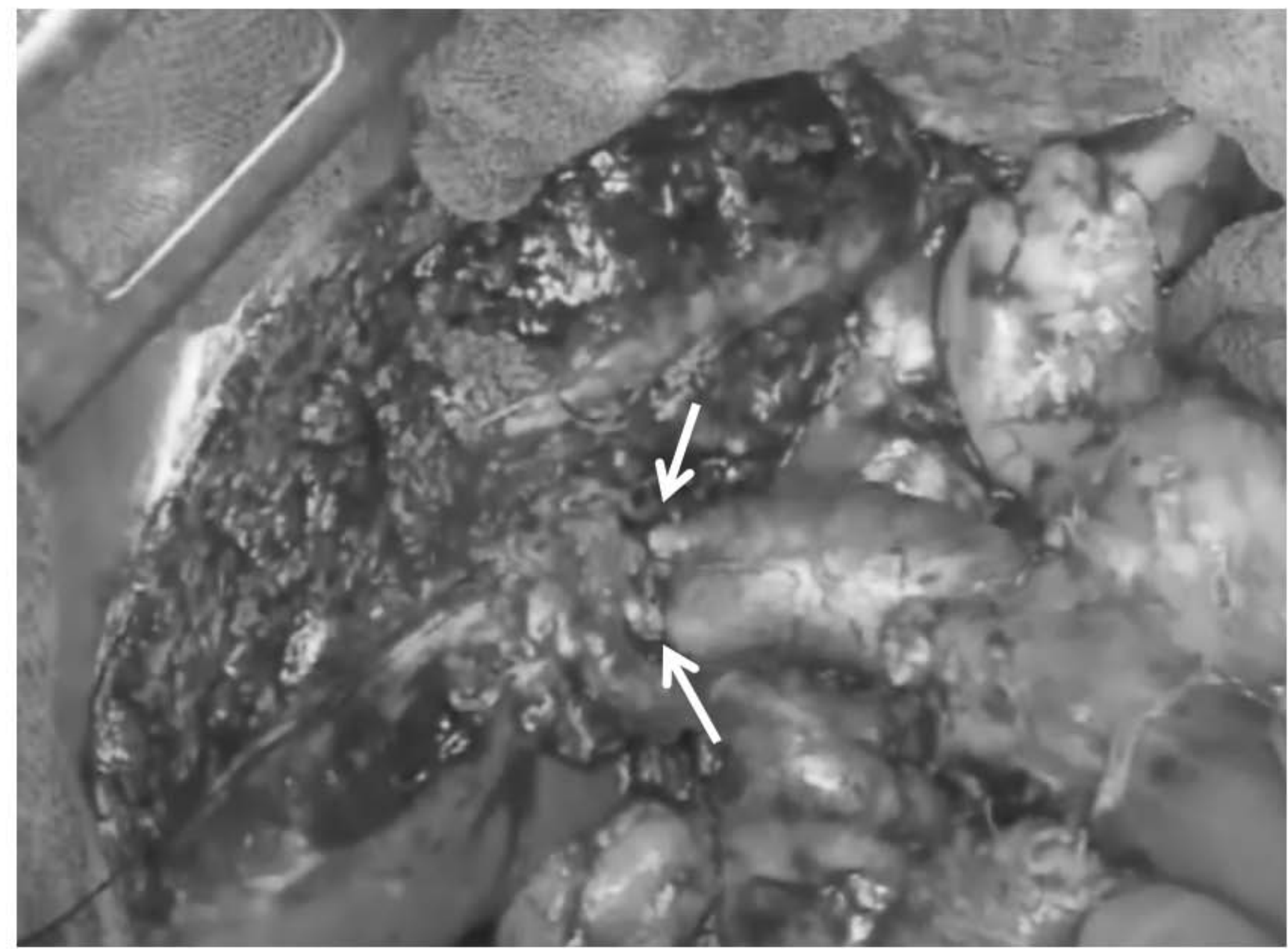


Fig3a

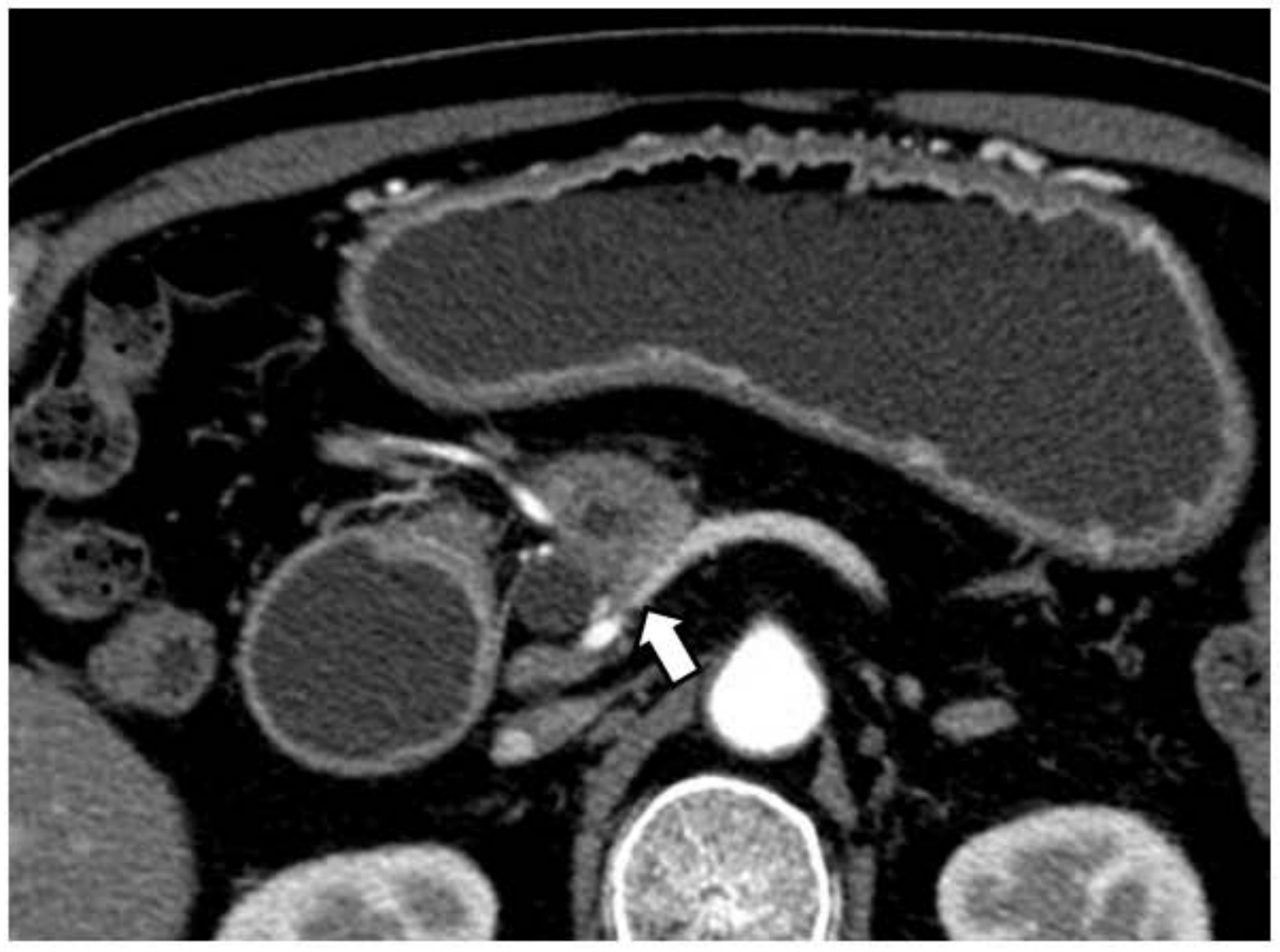


Fig3b

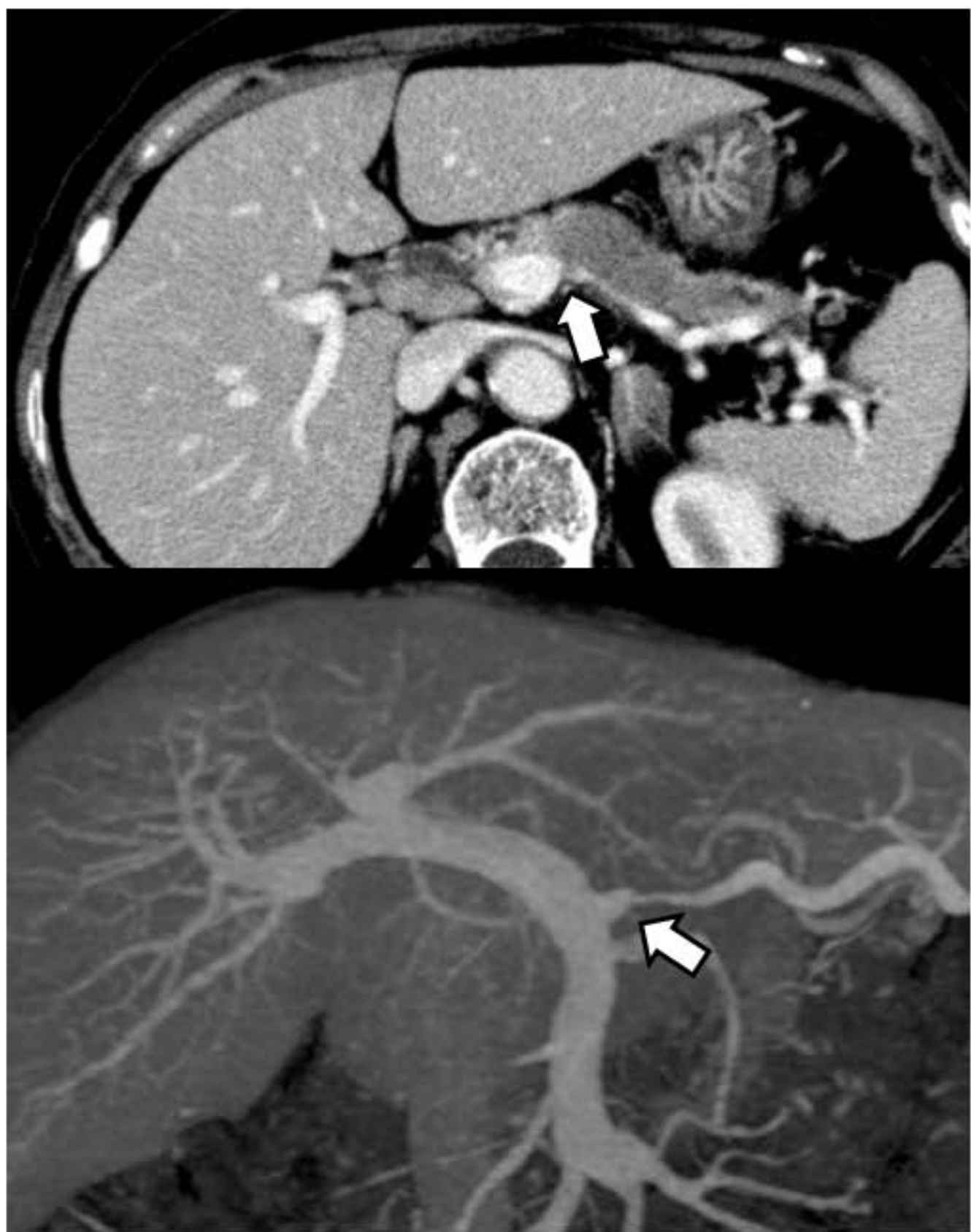


Fig3c

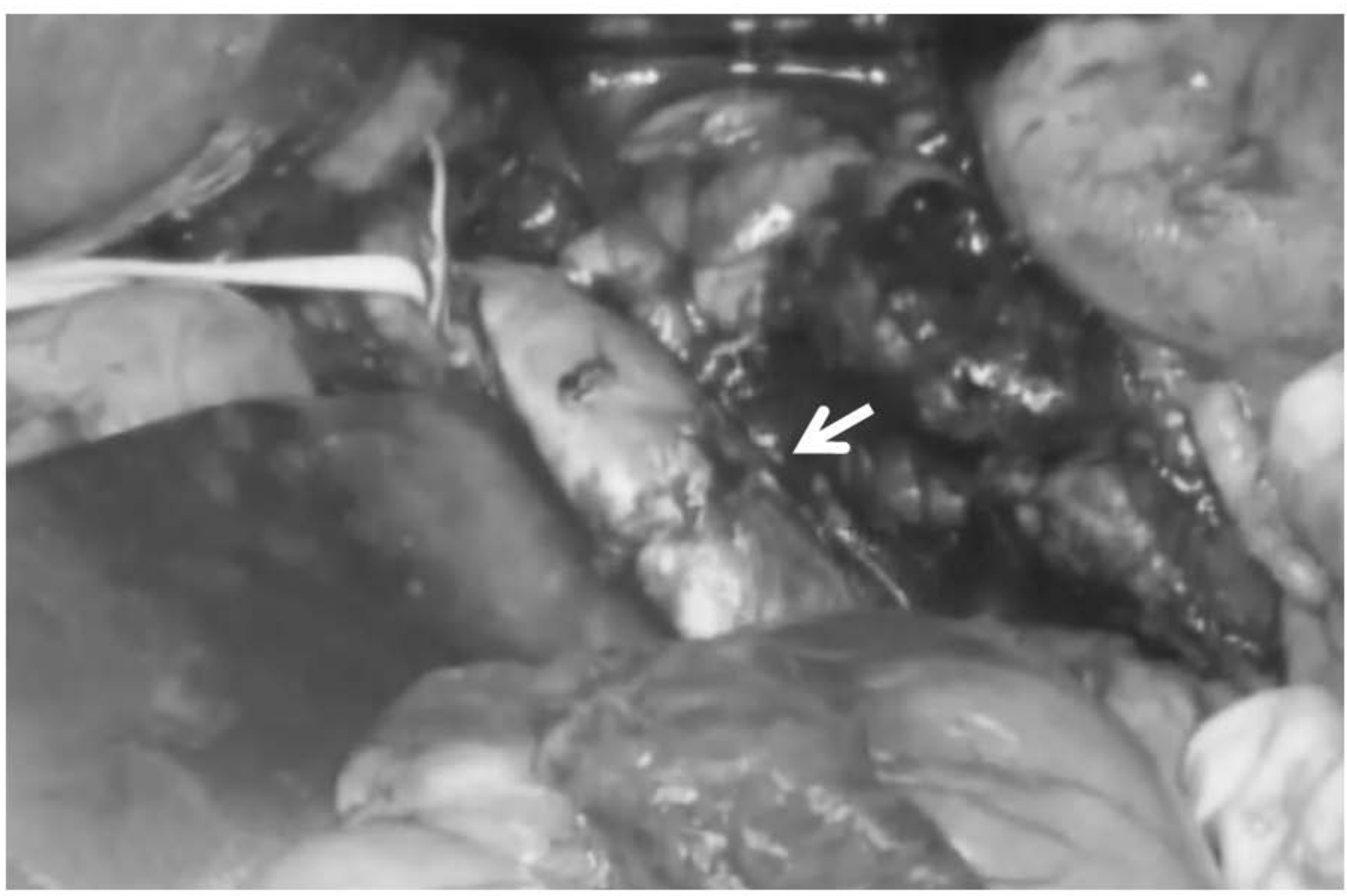

